\title{
Extending an invitation and providing a seat at the table: Tools and methods for diversifying the work force in universities and biotechs
}

Tsehai A..J. Grell

tgrell@fas.harvard.edu

Department of Molecular and Cellular Biology, Harvard University, Cambridge Massachusetts, Boston.

The terms diversity and inclusion have become buzz words across campuses and biotechs alike, with numerous articles and talks dedicated to understanding these topics. But even with all the buzz, questions about what these terms mean and more importantly how they translate to strategies that universities and biotechs can use to increase the diversity of classrooms, labs, and teams and to create an inclusive environment to promote a successful, content and efficient work force. During this talk we will navigate the terms diversity, inclusion and equity and discuss tools and strategies to increase diversity and promote inclusion in your respective teams, whether in academic or biotech settings. 